\title{
Tide-surge interaction in the English Channel
}

\author{
D. Idier ${ }^{1}$, F. Dumas ${ }^{2}$, and H. Muller ${ }^{1}$ \\ ${ }^{1}$ BRGM, 3 av. C. Guillemin, 45060 Orléans Cedex 02, France \\ ${ }^{2}$ IFREMER, Centre de Brest BP 70 - 29280 Plouzané, France \\ Correspondence to: D. Idier (d.idier@brgm.fr)
}

Received: 3 April 2012 - Revised: 29 October 2012 - Accepted: 11 November 2012 - Published: 19 December 2012

\begin{abstract}
The English Channel is characterised by strong tidal currents and a wide tidal range, such that their influence on surges is expected to be non-negligible. In order to better assess storm surges in this zone, tide-surge interactions are investigated. A preliminary data analysis on hourly surges indicates some preferential times of occurrence of large storm surges at rising tide, especially in Dunkerque. To examine this further, a numerical modelling approach is chosen, based on the 2DH shallow-water model (MARS). The surges are computed both with and without tide interaction. For the two selected events (the November 2007 North Sea and March 2008 Atlantic storms), it appears that the instantaneous tide-surge interaction is seen to be non-negligible in the eastern half of the English Channel, reaching values of $74 \mathrm{~cm}$ (i.e. $50 \%$ of the same event maximal storm surge) in the Dover Strait for the studied cases. This interaction decreases in westerly direction. In the risk-analysis community in France, extreme water levels have been determined assuming skew surges and tide as independent. The same hydrodynamic model is used to investigate this dependence in the English Channel. Simple computations are performed with the same meteorological forcing, while varying the tidal amplitude, and the skew surge differences $D_{\mathrm{SS}}$ are analysed. Skew surges appear to be tide-dependent, with negligible values of $D_{\mathrm{SS}}(<0.05 \mathrm{~m})$ over a large portion of the English Channel, although reaching several tens of centimetres in some locations (e.g. the Isle of Wight and Dover Strait).
\end{abstract}

\section{Introduction}

Recent events like Katrina (2005) or Xynthia (2010) illustrate the potentially devastating effect that storm surges can have on the coasts. Hurricane Katrina generated a storm surge exceeding $9 \mathrm{~m}$ in some locations along the Mississippi coastline (Blake et al., 2006) and was one of the six most powerful hurricanes ever recorded in the Atlantic, inflicting a death toll of 1836 and 80 billion dollars worth of damage. The Xynthia event was a mid-latitude storm resulting in a much smaller storm surge of about $1.5 \mathrm{~m}$, which coincided with a spring high tide. As a result, this event severely impacted low-lying coastal areas located in the central part of the Bay of Biscay on 27-28 February 2010 (Bertin et al., 2012), causing 53 fatalities and material damage assessed at more than one billion euros. Vivid memories of severe coastal disasters also attach to the 1953 and 1962 storm surge events, which caused flooding over broad coastal areas in the south-western Netherlands and eastern England (Gerritsen, 2005) and in northern Germany (von Storch et al., 2008), respectively. These examples illustrate the need for a better understanding of storm surge phenomena, as well as for improved water level forecast systems and land planning with respect to coastal flood risk.

Storm surges are known to have some potential interactions with tides (Flather, 2001). Indeed, many studies have investigated this dependence, either from a theoretical standpoint or in specific locations. Rossiter (1961) and Flather (2001) explain how tide and surge can mutually alternate their phase, in such a way that a positive (resp. neg.) surge would speed (resp. slow) the tidal propagation. By analysing the shallow-water equations in greater detail, the various contributions of the tide-surge interactions can be identified (Flather, 2001; Zhang et al., 2010): shallow-water effect (water depth), advective term, bottom friction term. For instance, Zhang et al. (2010), resp. Rego and Li (2010), investigated quantitatively the various contributions of the tide-surge interaction terms in the water-level, resp. in the Taiwan Strait and the North Sea, showing that, there, the dominant contribution comes from the nonlinear bottom friction. 
From an operational perspective, an understanding of this interaction is of value in order to choose relevant strategies in water level forecast or risk-analysis. Indeed, there are several possible approaches to forecast the water level on the coast induced by storm surges and tides. One (F1) is to numerically model storm surge and add it to the existing refined tidal database (e.g. the Nivmar system, Fanjul et al., 2001; NOAA system, Glahn et al., 2009). A second (F2) is to numerically compute the storm surge and the tide together (e.g. the North Sea forecast system operated by Rijkswaterstaat and The Royal Netherlands Meteorological Institute KNMI, and maintained by Deltares; the Previmer system www.previmer.org, maintained by Ifremer). For example, it will be noted that Horsburgh and Wilson (2007), concerning the North Sea, confirmed via data analysis that to obtain reliable forecasts of sea level, numerical models must accurately reproduce both tide and surges, and their interactions. A last strategy found in the literature (F3) is to numerically compute the storm surge and the tide together, but subsequently deduce the storm surge by subtraction, and finally add it to a more precise tide database (e.g. the UK's operational coastal flooded warning system, cf. Flather, 2000).

Regarding risk analyses, a knowledge of the extreme water level is required to provide the frequency of damages in the risk-analysis (Risk $=$ Hazard $\times$ Vulnerability $\times$ Frequency). Here again, more than one strategy can be implemented (Mazas and Hamm, 2011; Haigh et al., 2010). One (E1) is to apply the theory of extremes to the water level (Van den Brink et al., 2003, 2005). Another (E2), which seeks to procure a longer return period, is based on the same statistical theory, but applied to the skew storm surge, rather than the total water level. It will be recalled that the skew storm surge results from the difference between the highest (resp. lowest) water level and the highest (resp. lowest) predicted (tide) level, for a same high (resp. low) tide. The second step of strategy E2 is subsequently to combine the skew surge probability with the predictable tide probability afterwards (Simon et al., 2008).

We will note that the approaches F1 and E2 both implicitly assume the independence between, resp., instantaneous storm surge and tide, and skew storm surge and tide. In developing water level forecast systems or risk-analysis in a given area, the first step required is thus to select the relevant strategy, by analysing the actual dependence between storm surge and tide. In the context of developing a water level forecast system (www.previmer.org) along the French coastline, investigations have been carried out to ascertain the influence of tide on the storm surge, specifically in the English Channel. The aim of the present paper is to better assess this tidesurge interaction in the English Channel, and also to discuss the possible implications of the results for an extremes analysis regarding this area. First, Sect. 2 introduces the study area and some preliminary indications of interactions. Then, the method, model and data are presented (Sect. 3). In Sect. 4, the instantaneous storm-surge interactions are analysed. The

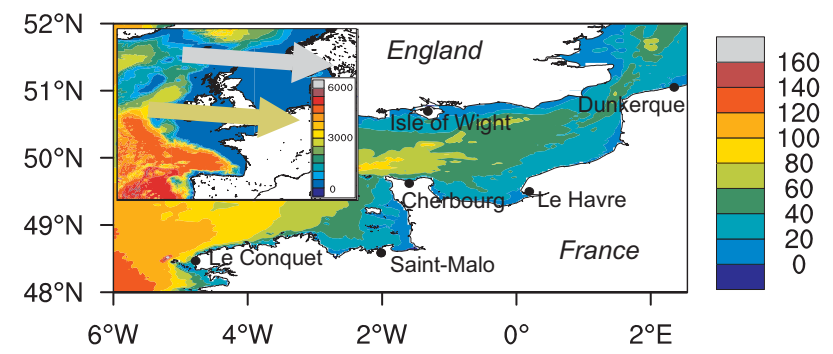

Fig. 1. Bathymetry (m) and study site location. The inset shows the model domain and charts the tracks of the studied depressions (grey: 8-9 November 2007; green: 9-10 March 2008).

implications for an extremes analysis are discussed (Sect. 5), and subsequently conclusions are drawn.

\section{The study area and preliminary evidence of tide-surge interactions}

The present study focuses on the English Channel (Fig. 1). This channel, lying between France and England, is characterised by mean spring tidal ranges varying between 1 (off the Isle of Wight) and $12 \mathrm{~m}$ (Saint-Michael's Mount Bay), and by associated maximal mean spring tidal currents ranging from a few $\mathrm{cm} \mathrm{s}^{-1}$ to about $5 \mathrm{~m} \mathrm{~s}^{-1}$ north-west of Cotentin headland (SHOM, 2000). Compared to the North Sea, the English Channel is subject to larger tidal ranges and tidal currents. Thus, given the fact that there are interactions between tide and storm surge in the North Sea and knowing that such interactions theoretically increase with increasing tidal range and tidal currents, we can expect some dependencies in the English Channel.

A preliminary analysis of tide gauge data has been achieved, over the period 2003-2009, for three locations: Dunkerque, Saint-Malo and Le Conquet. The whole hourly water level was processed by harmonic component analysis to extract the tide. Then, the hourly storm surge (termed practical storm surge in the present paper) was deduced by subtraction between the water level and the tide. The probability distribution of the $1 \%$ highest hourly storm surges for each gauge datum (Fig. 2) gives some indications of possible interaction between tide and storm surges. The weather is presumed independent of the tide, i.e. if the water level is a superposition of tide and surge, then the storm surge could occur at any time with respect to high water, and thus its distribution would accordingly be random. At Dunkerque, Fig. 2a shows that most of the largest practical storm surges occur around low tide, and, moreover $4-5 \mathrm{~h}$ before high tide (i.e. at rising tide). The same type of behaviour is observed at SaintMalo (Fig. 2b). Such phenomena have been most widely observed in the North Sea (Prandle and Wolf, 1979) and explained on the basis of theoretical considerations (Horsburgh and Wilson, 2007). The basic idea (at first order) is that tide 

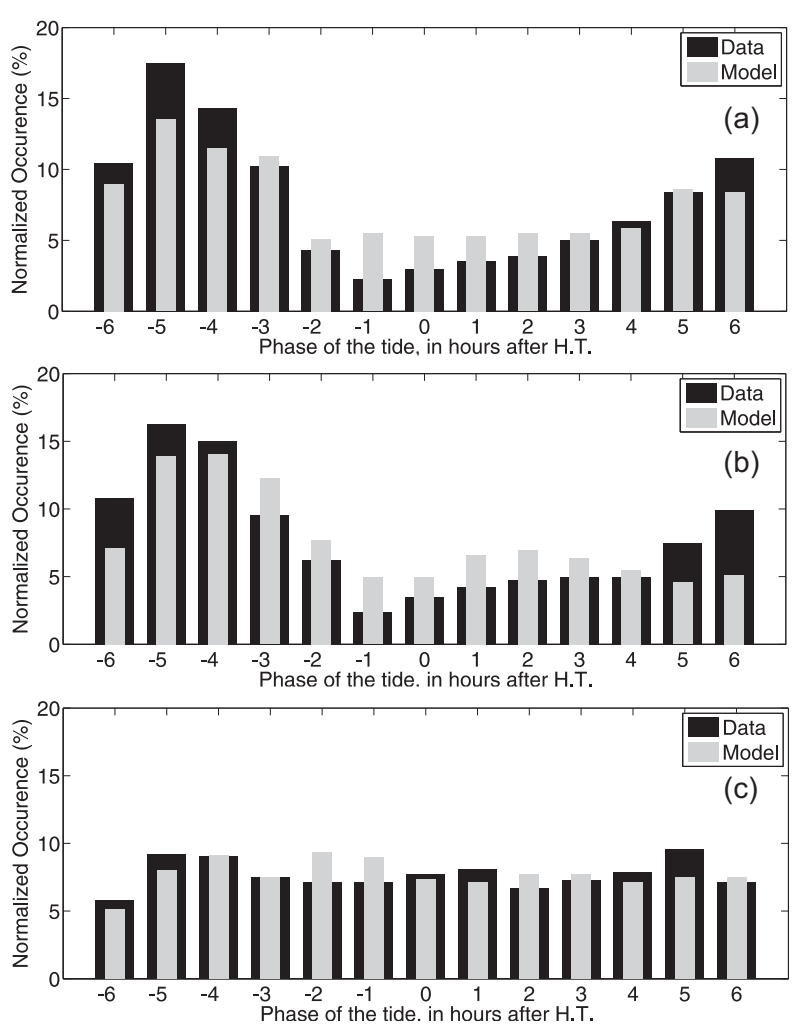

Fig. 2. Occurrence (\%) of the $1 \%$ highest observed (black) and modelled (grey) hourly storm surges versus the tidal phase, in hours after high tide (h) for: (a) Dunkerque, (b) Saint-Malo, (c) Le Conquet. The calculation is performed over the period 2003-2009. The 99th percentile (corresponding to the thresholds of the $1 \%$ highest storm surges) are $(0.65 ; 0.54),(0.43 ; 0.37),(0.37 ; 0.33)$, in metre, respectively for each tidal gauge location $(\mathbf{a}, \mathbf{b}, \mathbf{c})$, with the first value corresponding to the data processing, and the second, to the processing of the model results.

and surge are shallow-water waves propagating with a phase speed of $\sqrt{g D}$, where $D$ is the total water depth and $g$ the gravity acceleration. Increased water depth (induced, for instance, by a positive storm surge) would thus result in an increased phase speed of both surge and tide (directly, but also due to increased bed friction, friction being inversely proportional to water depth). Then, this increase would lead to a positive phase lag of the practical storm surge, such that the practical storm surge would occur preferably at rising tide. This is consistent with the results obtained by Sterl et al. (2009) on the influence of mean high tide on general extreme values (GEV) parameters in the North Sea, which show that the largest practical storm surge, $\xi_{\mathrm{SI}}$, occurs before the high tide. At Le Conquet (Fig. 2c), the largest practical storm surges do not occur preferably at one time more than another with respect to high tide, and there is accordingly no evidence of tide-surge interaction at this location.

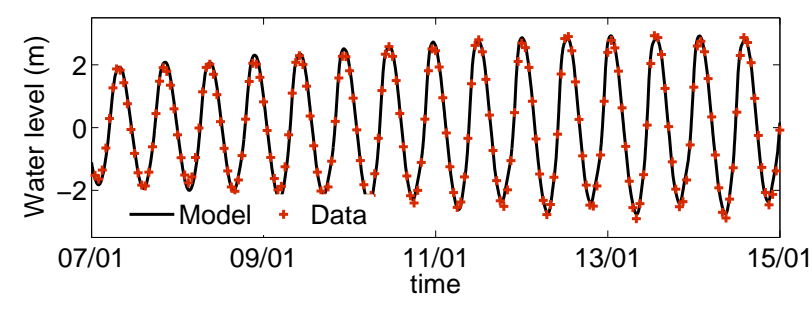

Fig. 3. Time series of predicted tide (based on data analysis done by the French Hydrographic Service, SHOM, 2009) and modelled tide (based on the MARS model and FES2004 forcing at the model boundaries). Site: Dunkerque.

In order to investigate tide-surge interactions more precisely, modelling is used to estimate the respective contributions of pure tide and surge.

\section{Method, model and data}

First, for the analysis of tide-surge interaction, following the terminology of Banks (1974), the water level $\xi$ can be written as the sum of the tidal level $\left(\xi_{\mathrm{T}}\right)$, the pure storm surge $\left(\xi_{\mathrm{S}}\right)$ produced by the meteorological conditions only, and the residual elevation due to tide-surge interaction $\left(\xi_{\mathrm{I}}\right)$, such that $\xi=\xi_{\mathrm{T}}+\xi_{\mathrm{S}}+\xi_{\mathrm{I}}$. In practice, the storm surge (termed practical storm surge, $\left.\xi_{\mathrm{SI}}\right)$ is often deduced from data by subtracting $\xi$ and $\xi_{\mathrm{T}}$, such that in fact $\xi_{\mathrm{SI}}=\xi_{\mathrm{S}}+\xi_{\mathrm{I}}$. Using numerical modelling, it is possible to estimate $\xi, \xi_{\mathrm{T}}$ and $\xi_{\mathrm{S}}$, such that we can deduce the residual elevation due to tide-surge interaction $\xi_{\text {I }}$. This is the basic idea underlying the method used in the present paper.

Comparing 3-D and 2-D models for storm surge modelling, Dukhovskoy and Morey (2011) recall that 2-D approaches have two main drawbacks: the bottom friction parametrisation, which is dependent on the depth-averaged flow and not on the bottom stress, and the resolution of the vertical flow structure (in case of vertical shear). However, the 2-D shallow-water model did turn out to reproduce storm surges well (Bertin et al., 2012). Thus, in the present study, a 2-D approach is chosen, with a preliminary validation of its ability to reproduce observed surges and tide-surge interaction. The selected numerical model is MARS, based on shallow-water equations (Lazure and Dumas, 2008). The Fig. 1 inset shows the computational domain. It covers a much larger area than the English Channel in order to properly reproduce storm surges generated at greater distance in the Atlantic or North Sea. The grid size is $2 \mathrm{~km}$. In the present model, the drag coefficient that allows the air-sea momentum flux to be taken into account depends on waves and wind. It should be noted that the drag coefficient is generally used as a tuning parameter in storm surge models (Zweers et al., 2012). In our model, the air-sea momentum flux is parametrised by a non-dimensional surface roughness length, $z_{0}$, based on the 
Table 1. Observed and modelled 0.5, 1 and 2-yr return period storm surges (in metres). Results obtained for a data processing over the period 2003-2009.

\begin{tabular}{|c|c|c|c|c|c|c|}
\hline & \multicolumn{2}{|c|}{$T=0.5 \mathrm{yr}$} & \multicolumn{2}{|c|}{$T=1 \mathrm{yr}$} & \multicolumn{2}{|c|}{$T=2 \mathrm{yr}$} \\
\hline & Obs & Model & Obs & Model & Obs & Model \\
\hline Dunkerque & 1.19 & 0.96 & 1.41 & 1.14 & 1.59 & 1.28 \\
\hline Saint-Malo & 0.75 & 0.60 & 0.89 & 0.70 & 1.02 & 0.79 \\
\hline Le Conquet & 0.51 & 0.43 & 0.59 & 0.49 & 0.93 & 0.83 \\
\hline
\end{tabular}

Charnock (1955) formulation, such that the roughness length is a function of the wave characteristics (Tolman , 2009). The bed shear stress is computed using a Strickler coefficient of $35 \mathrm{~m}^{1 / 3} \mathrm{~s}^{-1}$. As tidal forcing, the 14 tidal components $(M f$, $M m, M s q m, M t m, O 1, P 1, Q 1, K 1, M 2, K 2,2 N 2, N 2, S 2$ and M4) are used, derived from the global tidal model FES2004 (Lyard et al., 2006). Concerning meteorological forcing, a 3$\mathrm{h}$ ARPEGE data set (provided by Meteo-France) based on a 6-h time-step analysis, completed by 3-h time-step predictions, is used. The ARPEGE grid size is $0.5^{\circ}$, i.e. about $50 \mathrm{~km}$. The last input is the wave data, used to compute the Charnock coefficient in every cell and for every time step, and then the drag coefficient $C_{\mathrm{D}}$. These data derive from modelling work carried out with the WW3 model (Rascle and Ardhuin, 2012). Such approach yields drag coefficients $C_{\mathrm{D}}$ of about 0.0025 to 0.0035 for stormy events. These values are on the same order of magnitude as those obtained by Moon et al. (2004).

The model's ability to reproduce the tide, the storm surge and the tide-surge interaction is assessed by comparison with data. First, the tide is evaluated at Dunkerque, Saint-Malo and Le Conquet and displays a good correlation (correlation coefficient of 0.99) with the tidal prediction of the French Hydrographic Service (SHOM). Figure 3 illustrates how effectively the tide was reproduced by the model at Dunkerque. To validate the surge, observed and modelled surges are rendered comparable. The observed and modelled water level (including tide and meteorological forcings) are processed over a 7-yr time span. First, a tidal component analysis is performed (Simon, 2007), then the tide is subtracted from the total water level. Table 1 demonstrates the model's ability to reproduce observed surges at this scale, focusing on surges with return periods of $0.5,1$ and $2 \mathrm{yr}$. In addition, Fig. 4 illustrates the model's ability for two stormy events (presented later on in the paper). Finally, the model's capacity to properly reproduce tide-surge interaction is investigated, based on comparison with observed data. Figure 2 shows the distribution of the $1 \%$ highest storm surges versus the tidal phase. The model exhibits behaviour similar to that of the data. These comparisons confirm that the model can validly be used to study tide-surge interaction.

To investigate and quantify the elevation $\xi_{I}$, three types of runs are effected: one with full forcing (tide, wind, atmospheric pressure) which yields $\xi$, one with tide only yielding
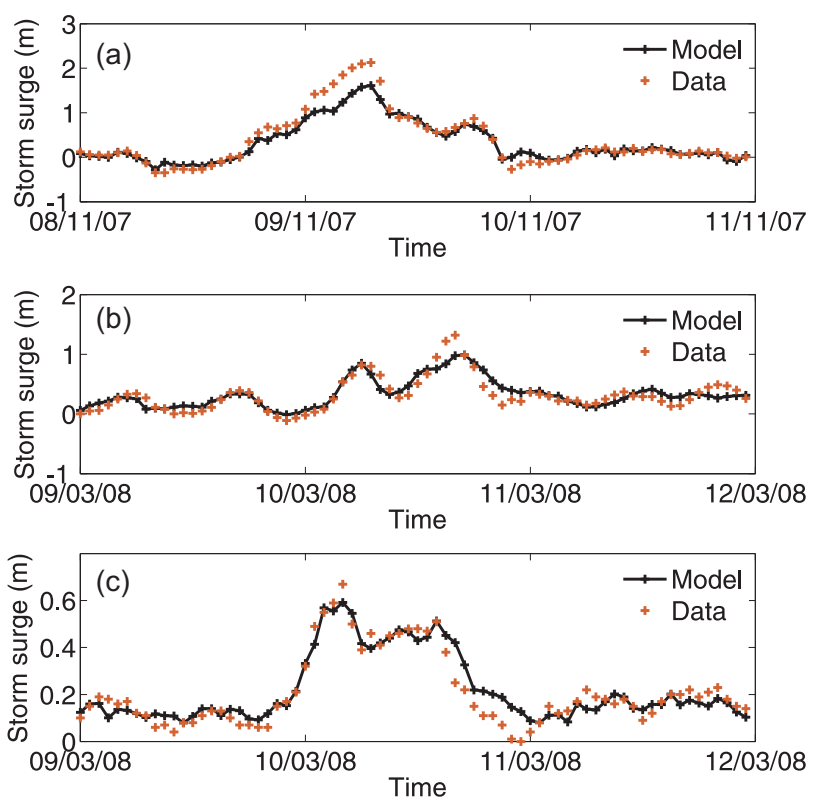

Fig. 4. Time series of observed and modelled practical storm surge for the November 2007 event (Dunkerque, a) and the March 2008 event (at Saint-Malo, b, and Le Conquet, c). Observed and modelled data have been processed accordingly to exactly the same procedure, and over the same time span (the tidal component has been computed based on observed and modelled water level over the period 2003-2009).

$\xi_{\mathrm{T}}$, and one with meteorological forcing only (wind, atmospheric pressure) yielding $\xi_{\mathrm{S}}$. Besides, in order to obtain a representative view of tide-surge interactions in the English Channel, we focus on two storm events, schematized on Fig. 1: one from North Sea (November 2007), and another from the Atlantic (March 2008).

\section{Tide-surge interaction}

\subsection{Results}

Figure 5 shows the maximal value of the hourly practical storm surge $\xi_{\mathrm{SI}}$ and of the hourly tide-surge interaction elevation $\xi_{I}$, for the two selected events. For the November 2007 event (Fig. 1), we notice strong storm surges, exceeding $1.5 \mathrm{~m}$ in some locations, all over the North Sea with a gradual decrease in the English Channel, up to the Cotentin headland, where the maximum practical storm surge falls below $0.1 \mathrm{~m}$. Considering the interaction elevation $\xi_{\text {I }}$, it would appear to be stronger in the southern part of North Sea as well as in the English Channel, attaining values greater than $0.6 \mathrm{~m}$, especially in the Somme Bay, to the west of Dunkerque. For the second event, that of March 2008, associated with a depression coming from Ireland (Fig. 1), the maximal storm surges are smaller than for the November 2007 event, in the English Channel, with values lower than $1.5 \mathrm{~m}$. Regarding the 

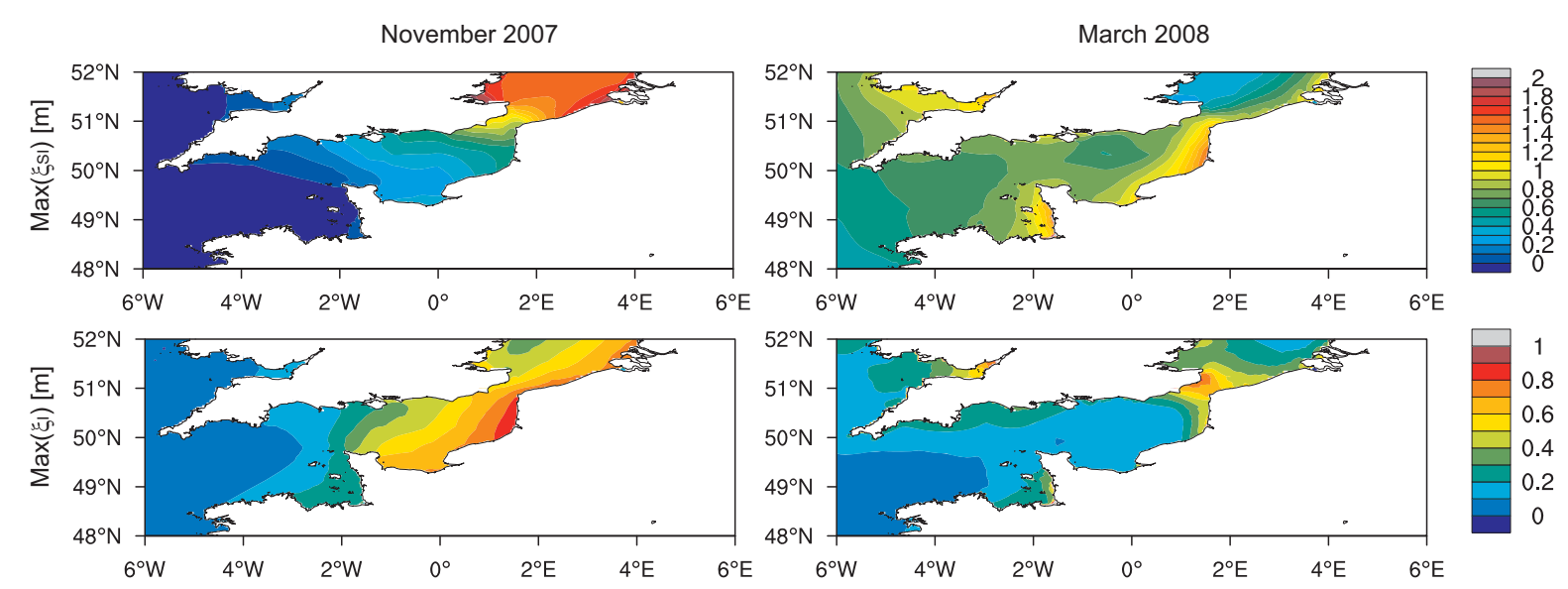

Fig. 5. Maximum value of the practical storm surge $\xi_{\mathrm{SI}}$ (left) and the residual tide-surge interaction elevation $\xi_{\mathrm{I}}$ (right), for the two events of November 2007 (above) and March 2008 (below). Data interval: 12-min.

Table 2. Synthesis of characteristics values of practical storm surge $\xi_{\text {SI }}$ and tide-surge interaction elevation $\xi_{\text {I }}$ for the studied events (Ev. 1: November 2007; Ev. 2: March 2008) and locations. Time $t_{\mathrm{S}}$ indicates the time at which $\left|\xi_{\mathrm{SI}}\right|$ is highest during the event. Numbers in italics indicate the corresponding value of $\xi_{\text {SI }}$ or $\xi_{\text {I }}$ when it is negative.

\begin{tabular}{lcccccccc}
\hline & \multicolumn{2}{c}{ Dunkerque } & & \multicolumn{2}{c}{ Saint-Malo } & & \multicolumn{2}{c}{ Le Conquet } \\
\cline { 2 - 3 } & Ev. 1 & Ev. 2 & & Ev. 1 & Ev. 2 & & Ev. 1 & Ev. 2 \\
\hline $\max \left(\left|\xi_{\text {SI }}\right|\right)(\mathrm{m})$ & 1.49 & 0.90 & & 0.25 & 0.93 & & 0.26 & 0.58 \\
$\max \left(\left|\xi_{\mathrm{I}}\right|\right)(\mathrm{m})$ & 0.74 & 0.51 & & 0.26 & 0.28 & & 0.09 & 0.09 \\
$\xi_{\mathrm{I}}\left(t_{\mathrm{S}}\right)(\mathrm{m})$ & 0.37 & 0.51 & & 0.01 & 0.26 & & 0.03 & 0.03 \\
\hline
\end{tabular}

tide-surge interaction, the maximal value of $\xi_{\mathrm{I}}$ is about $0.3 \mathrm{~m}$ in some areas, and reaches $0.7 \mathrm{~m}$ in a limited area, around the Dover Strait.

Water level time series and statistical analysis of $\xi_{\text {SI }}$ and $\xi_{\text {I }}$ allow the analysis to be completed at the three locations of Dunkerque, Saint-Malo and Le Conquet. First, we consider the example of the November 2007 event (Fig. 6). The tidesurge interaction elevation $\xi_{\text {I }}$ decreases from Dunkerque towards Le Conquet, and can be positive or negative depending on the time and location. It reaches $0.74 \mathrm{~m}$ at Dunkerque, for a maximal practical storm surge $\xi_{\text {SI }}$ of $1.49 \mathrm{~m}$ (Table 2), such that it is equal to about $50 \%$ of $\xi_{\mathrm{SI}}$. At Le Conquet, $\xi_{\mathrm{SI}}$ is mainly negative, reaching $-0.25 \mathrm{~m}$, whereas $\xi_{\mathrm{I}}$ is comprised between 0.09 and $-0.03 \mathrm{~m}$ (Table 2), i.e. equal to about one third of $\left|\xi_{\text {SI }}\right|$. It is of note that $\xi_{\text {SI }}$ and $\xi_{\text {I }}$ maxima do not occur at the same time (Fig. 6). In agreement with the preliminary data analysis on the surge distribution with tidal phase (Fig. 2), Fig. 6 shows that, for stormy events at locations where tide-surge interaction was detected in Sect. 2, the maximum of $\xi_{\text {SI }}$ occurs 4 to $5 \mathrm{~h}$ before high tide at Dunkerque (November 2007 and March 2007) and $3 \mathrm{~h}$ before high tide at Saint-Malo (March 2008). These peaks cor- respond to local maxima of $\xi_{\mathrm{I}}$, but not to the absolute maximum value of $\xi_{\text {I }}$ during the event, as illustrated by the time series for Dunkerque, where the maximum of $\xi_{\text {I }}$ occurs $6 \mathrm{~h}$ after high tide. Thus, to complete the analysis, we focus on

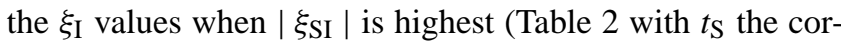
responding time). For Dunkerque, $\xi_{\mathrm{I}}\left(t_{\mathrm{S}}\right)$ respectively equals 0.37 and $0.51 \mathrm{~m}$ for the 2007 and 2008 events, i.e. 25 and $57 \%$. For Saint-Malo, it also reaches $28 \%$ of the maximum practical storm surge (March 2008 event, $\xi_{\mathrm{I}}\left(t_{\mathrm{S}}\right)=0.26 \mathrm{~m}$ ). For Le Conquet, the contribution is lower, reaching $12 \%$ of the maximum practical storm surge (November 2007 event, $\left.\xi_{\mathrm{I}}\left(t_{\mathrm{S}}\right)=-0.03 \mathrm{~m}\right)$. To sum up the results for the studied events, $\xi_{\mathrm{I}}$ is large at Dunkerque (up to $0.74 \mathrm{~m}$ ) moderate at Saint-Malo (up to $0.26 \mathrm{~m}$ ), and smaller at Le Conquet (up to $9 \mathrm{~cm}$ ), whereas its relative value for $t=t_{\mathrm{S}}$ is still large at Dunkerque (up to $51 \%$ ), and moderate at Saint-Malo and Le Conquet (up to $28 \%$ ).

From these two studied events, we can deduce that tidesurge interactions are significant in a large eastern part of the English Channel, and moreover in the Dunkerque surroundings, with large surges occurring preferably before the high tide. Such types of comparisons were performed for the February events of 2009 (Quentin) and 2010 (Xynthia), yielding similar results.

\subsection{Analysis}

These tide-surge interactions can be explained by means of the physical equations. Indeed, shallow-water equations can be written as follows, omitting the horizontal viscosity term $\left(A \nabla^{2} \mathbf{u}\right)$ for the sake of clarity: 

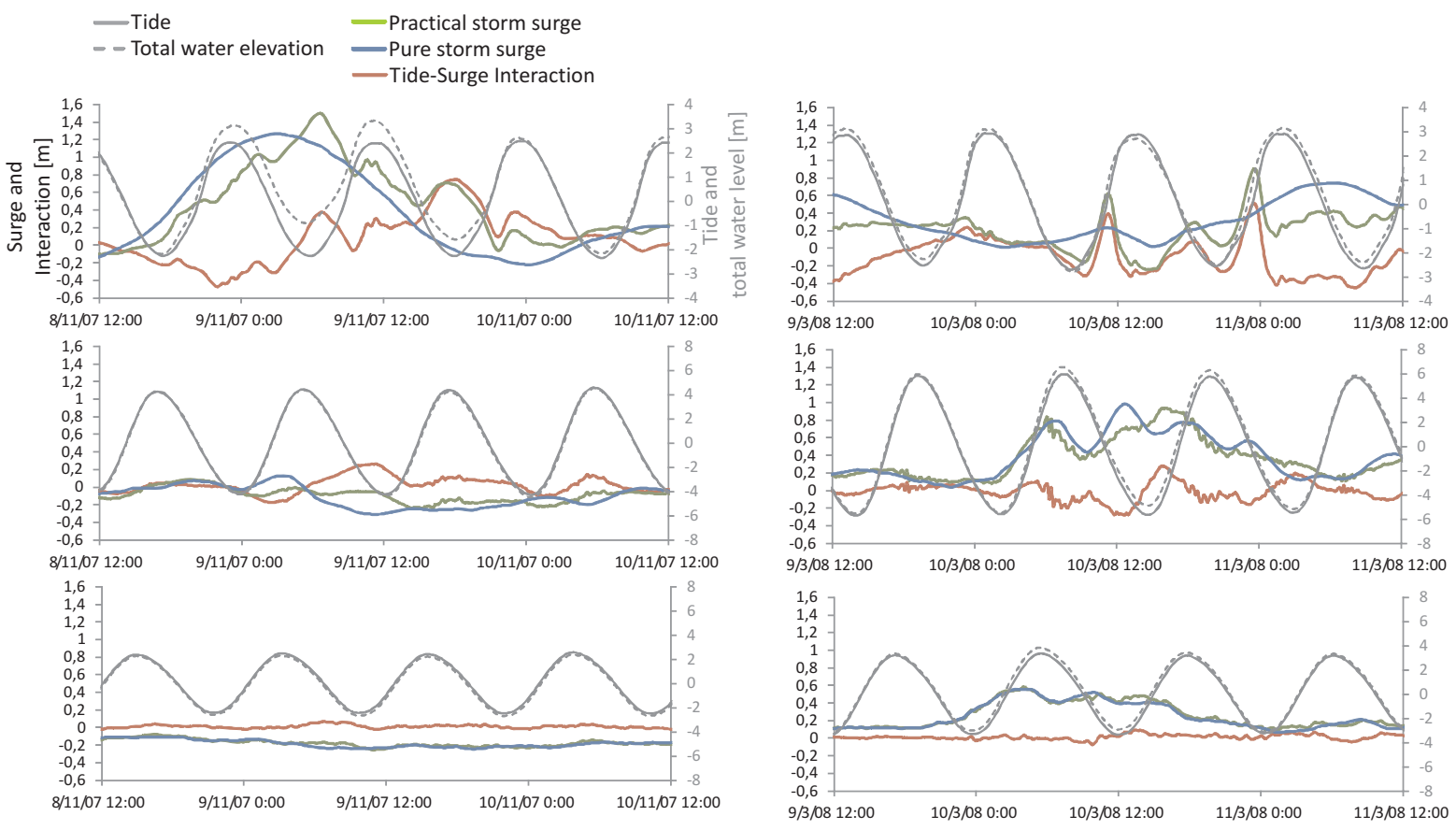

Fig. 6. Time series of the various components of the water elevation $\xi$ at: Dunkerque (top), Saint-Malo (middle), Le Conquet (bottom), for the November 2007 (left) and March 2008 (right) events.

$$
\begin{aligned}
& \frac{\partial \xi}{\partial t}+\nabla \cdot(D \mathbf{u})=0 \\
& \frac{\partial \mathbf{u}}{\partial t}+\mathbf{u} \cdot \nabla \mathbf{u}-f \boldsymbol{k} \cdot \mathbf{u}=-g \nabla(\xi-\bar{\xi})+\frac{1}{\rho} \nabla p_{\mathrm{a}} \\
& \quad+\frac{1}{\rho D}\left(\boldsymbol{\tau}_{\mathrm{s}}-\boldsymbol{\tau}_{\mathrm{b}}\right)
\end{aligned}
$$

with $\mathbf{u}$ the depth-integrated current, $\xi$ the free surface, $D$ the total water depth (equal to the sum of undisturbed water depth $H$ and the free surface elevation $\xi$ ), $\rho$ the density of sea water, $g$ the gravity acceleration, $p_{\mathrm{a}}$ the atmospheric pressure, $f$ the Coriolis parameter $(2 \omega \sin \phi$, with $\omega$ the angular speed of Earth rotation and $\phi$ the latitude) and $\boldsymbol{k}$ a unit vector in the vertical. $\boldsymbol{\tau}_{\mathrm{b}}$ and $\boldsymbol{\tau}_{\mathrm{s}}$ are respectively the bed and wind shear stress. The quatratic law is applied in the parametrisation of $\boldsymbol{\tau}_{\mathrm{b}}$ and $\boldsymbol{\tau}_{\mathrm{s}}$ such that:

$$
\begin{array}{r}
\boldsymbol{\tau}_{\mathbf{b}}=\rho g \mathbf{u}|\mathbf{u}| / K^{2} D^{1 / 3} \\
\boldsymbol{\tau}_{\mathbf{s}}=\rho_{\mathrm{a}} C_{\mathrm{D}} \mathbf{U}_{\mathbf{1 0}}\left|\mathbf{U}_{\mathbf{1 0}}\right|
\end{array}
$$

where $K$ is the Strickler coefficient, $C_{\mathrm{D}}$ is the free surface drag cofficient, $\rho_{\mathrm{a}}$ is the air density and $\mathbf{U}_{\mathbf{1 0}}$ is the wind velocity at $z=10 \mathrm{~m}$.

In Eqs. (1), (2) and (3), as highlighted by Zhang et al. (2010), there are several nonlinear terms which can be classified in three nonlinear effects:

- the advective effect, arising from the advective terms of the momentum Eq. (2).
- the shallow-water effect which arises from nonlinear terms related to $D=(H+\xi)$ in Eqs. (1), (2) and (3) in the following places: advective term of continuity equation, division by depth for the bed-friction term and division by depth for the wind-forcing term.

- the nonlinear effect of the bottom friction term with quadratic parametrisation in Eq. (3).

Thus, tidal current and tidal water level interact directly with the hydrodynamics induced by wind and pressure, through the advection term, the so-called shallow-water effect (water height in the denominator of the friction term) and nonlinear friction term related to velocity interactions (Flather, 2001; Zhang et al., 2010). Moreover, in many cases, the dominant tide-surge interaction term comes from the friction term. As an example of a similar environment, we can refer to the Zhang et al. (2010) study on Taiwan Strait. They numerically show that the quadratic nonlinear friction term contributes significantly to tide-surge interaction, as compared to the advective term and the shallow-water effect.

The present results obtained in the English Channel reveal that tide-surge interaction appears to be pronounced in the area comprised between Saint-Malo and the North Sea, for the studied events. We discuss the contributions of these effects in the tide-surge interaction pattern, based on the analysis of the above equation.

Regarding the effect of the nonlinear advective term, the tidal current pattern in the English Channel is highly 
heterogeneous and locally strong, with mean spring tide currents ranging from 1 to $5 \mathrm{~m} \mathrm{~s}^{-1}$ between Cherbourg and England (SHOM, 2000), whereas in the middle western part of the English Channel, the tidal currents are much smaller. Moreover, in some areas, tidal currents are large as compared to the storm induced currents. For instance, around the Dover Strait, tidal and storm-induced currents may be on the same order of magnitude (Idier et al., 2002). This tidal current pattern should imply interactions in nonlinear advection terms in the Dover Strait that are larger than those offshore Brittany.

The shallow-water effect depends on the relative magnitude of the water depth $H$, the tidal level and the storm surge. The tidal range in the entire English Channel (on average, about $6 \mathrm{~m}$ for a mean spring tide, SHOM (2000)) is most often larger than the storm surge (1-yr return period storm surge smaller than $1 \mathrm{~m}$ everywhere along the French coast; Simon et al., 2008), contributing to tide-surge interaction more or less all over the English Channel. However, the water depth $H$ in the eastern part of the English Channel is smaller (about $50 \mathrm{~m}$ ) than in the western part, implying that the shallowwater effect should be larger in the Eastern part. For instance, this effect contributes to the modulated surge production. Indeed, under some assumptions (mainly 1-D flow and constant wind field) Pugh (1987) shows that the sea surface slope $(\partial \xi / \partial x)$ is in equilibrium with $C_{\mathrm{D}} U_{10}{ }^{2} / D$, such that the wind stress produces more surge in shallow water, and thus at low tide than at high tide, other things being equal. As explained by Horsburgh and Wilson (2007), such phenomena can lead to an increase in the phase lag of the practical storm surge compared to the tide, such that the storm surge can precede high water by more than four hours. This behaviour can be identified for instance during the November 2007 event at Dunkerque (Fig. 6).

Wolf (1978) investigated the contribution of the non-linear friction term to the tide-surge interaction. In that study, the definition is slightly different with the quadratic friction term including the water depth variations, i.e. one part of the shallow-water effect. They solved analytically the motion equation of two plane progressive waves travelling together in a semi-infinite uniform channel, the waves being the surge and the tide. The second-order solution allows identifying the contribution of the three effects (shallow-water, advective and nonlinear friction) in the tide-surge interaction. They show that the increase of $\xi_{\text {I }}$ on rising tide is due to shallow water and advection effect, whereas the quadratic friction effect tends to reduce $\xi$ at high tide. These results were obtained for conditions quite similar to the ones of the overall English Channel, in terms of water depth $(40 \mathrm{~m})$ and surge amplitude (0.4 to $1 \mathrm{~m}$ ), and for a quadratic friction term (like in our model). However, the tidal conditions were smaller (tidal range of $1 \mathrm{~m}$ ). With these conditions, and investigating all the possible hourly phase lags between tide and surge, they obtain interactions reaching about $14 \mathrm{~cm}$ at the southern North Sea $(700 \mathrm{~km}$ from the northern North Sea entrance),

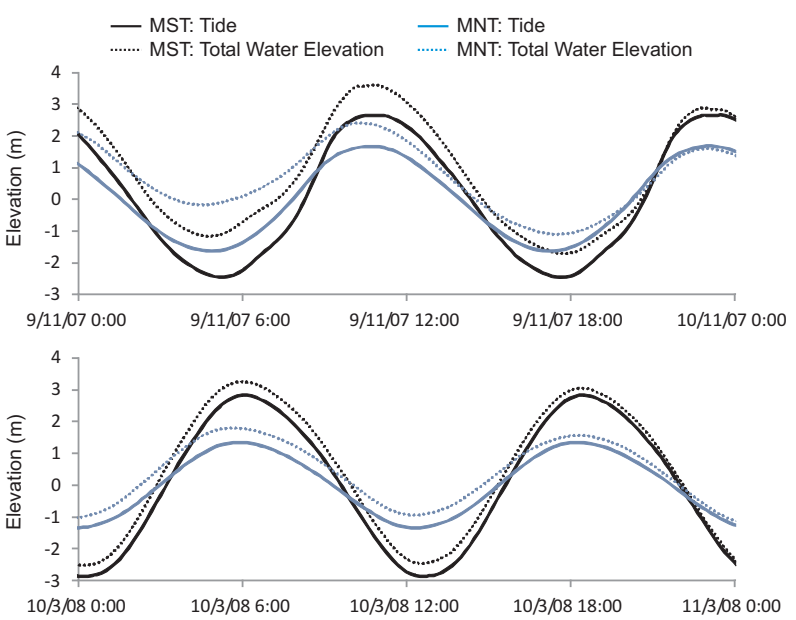

Fig. 7. Time series of tide and total water elevation for mean neap and spring tide (M2-modulated on the boundaries) at Dunkerque for the November 2007 event (above), and Le Conquet for the March 2008 event (below).

due to the friction effect alone. Using these equations, and increasing the tidal range to $6 \mathrm{~m}$ (representative of the English Channel for a mean spring tide), we obtain friction effect that is four times larger, i.e. interaction of tenths of centimetres, due to the quadratic friction effect alone. Besides, as suggested by Zhang et al. (2010), the alignment of tidal and meteorological induced currents can also contribute to explaining of the strong (resp. small) tide-surge interaction at the Dover Strait (resp. northern Brittany) trhough the friction term. Indeed, in the Dover Strait, flood and ebb current have mostly the same direction (at least for energetic events) as the storm-induced ones (Idier et al., 2002, 2011), whereas for events coming from the Atlantic, at the entrance to the Channel, storm-induced currents do not have time to be constrained enough by the morphology and the coast, and thus are less aligned with the ebb/flood currents. As explained by Zhang et al. (2010), from Eq. (2), the increased force of bed stress due to the alignment of tidal and storm-induced current is offset by the pressure gradient force (surface slope) and then the surge residual $\left(\xi_{\mathrm{I}}\right)$, such that tide-surge interaction is intensified by the channelling effect of the strait. The tidal current is periodic, and accordingly this interaction process is also periodic and results in oscillations of $\xi_{\text {I }}$ with the tidal period during stormy events (see the results at Dunkerque, Fig. 6).

Thus, the large (resp. weak) tide-surge interaction in the eastern (resp. western) part of English Channel can be interpreted as resulting from the bathymetry and the two tidal contributions (current and free-surface elevation) patterns, with an expected contribution from the friction term of tenths of centimetres. 

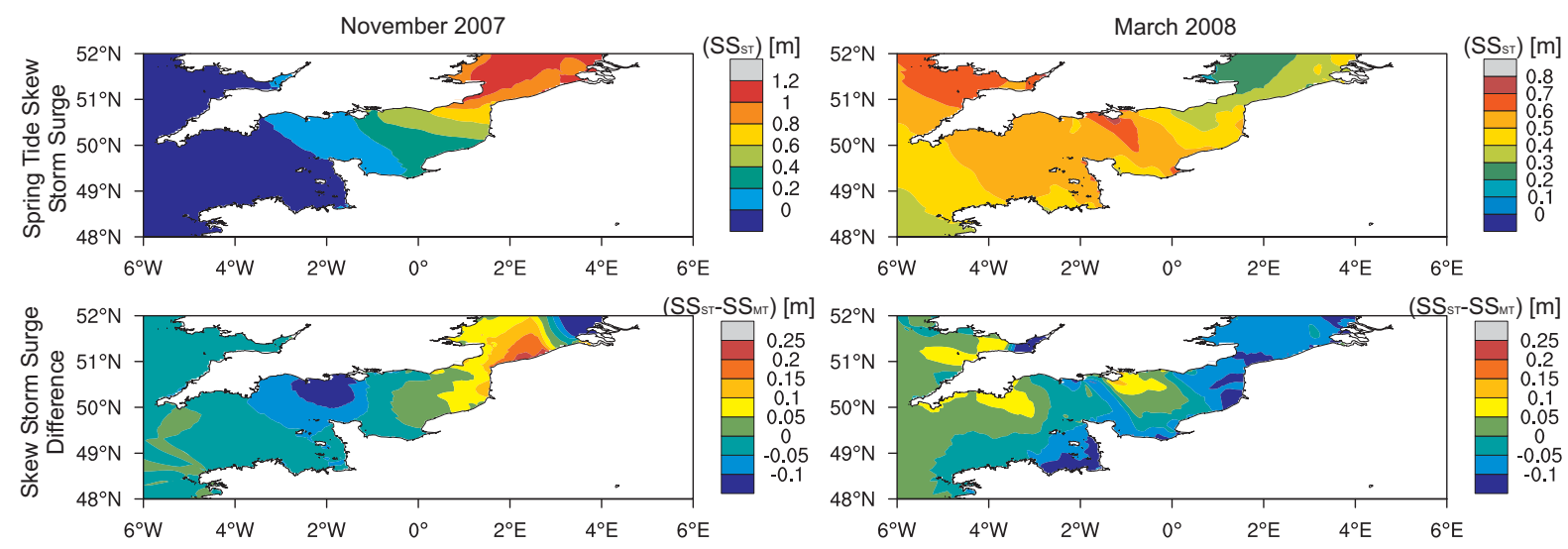

Fig. 8. High tide skew storm surges for mean spring tide (left) and the difference between skew storm surges obtained for a mean neap tide and a mean spring tide (right), for the November 2007 (above) and March 2008 (below) events. The meteorological forcing is the same as in Fig. 5. Data interval: 12 min.

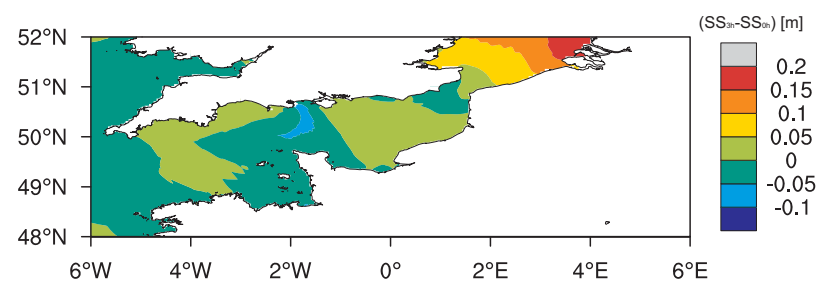

Fig. 9. Difference between high tide skew storm surges obtained for a meteorological phase lag of $3 \mathrm{~h}$ (as compared with the original meteorological conditions) and the skew storm surges obtained for the original meteorological conditions (zero phase lag). The simulation is performed for a mean spring tide and for the November 2007 event. Data interval: $12 \mathrm{~min}$.

\section{Skew surges at high tide and implication for extremes analysis}

Figure 6 shows that $\xi_{\text {I }}$ exhibits some temporal periodicity with positive and negative values, but also several local maxima (e.g. at Dunkerque in November 2007: the largest maximum occurs at low tide, and the smallest one just before high tide). These temporal fluctuations indicate that the interpretation of the existing instantaneous tide-surge interaction in terms of flooding risks and return levels is not straightforward. To better analyse what the implications in terms of risks are, some complementary investigations are carried out, focusing on the skew surges. The results above show that the instantaneous storm surge is related to the tide. Then, we can wonder what happens with the skew storm surges: does it depend on the tide? To look into this question, complementary tests are carried out. They consist in computing the events of November 2007 and March 2008 with two M2-modulated tides, corresponding respectively to a mean neap tide (MNT), and a mean spring tide (MST). For each case, two simulations are performed: one with tide only (MNT1 and MST1), one with tide and meteorological forcing conditions (MNT2 and MST2). The skew storm surge at high tide is then computed for each case (the two fictitious tides and the two meteorological events).

First, tides times series (mean neap and mean spring), for the two selected events (November 2007 and March 2008), show that it is not just a sinusoidal signal of changing amplitude (Fig. 7). Indeed, an M2 signal is imposed at the boundary conditions, with just a modulation of the amplitude. While tide propagates over the continental shelf, harmonics are generated, rendering the signal no longer sinusoidal. Figure 7 also indicates the total water elevation. For the November 2007 event at Dunkerque, the high tide skew storm surge $(0.97 \mathrm{~m})$ is significantly larger than the one for the mean neap tide $(0.73 \mathrm{~m})$. For the March 2008 event, at Le Conquet, the high tide skew storm surges are close for mean spring tide $\left(\mathrm{SS}_{\mathrm{MST}}=0.43 \mathrm{~m}\right)$ and mean neap tide $\left(\mathrm{SS}_{\mathrm{MNT}}=0.45 \mathrm{~m}\right)$. Indeed, for the November 2007 event at Dunkerque, the practical storm surge is much larger for the spring tide than for the neap tide (not shown here), whereas for the March 2008 event, skew storm surges are similar for both the mean spring tide and the mean neap tide (not shown here). This is in agreement with the results of the previous section (tide-surge interactions significant in the eastern part of the English Channel and negligible at Le Conquet).

From a spatial point of view, Fig. 8 shows, for the two events, the skew surge SS $_{\text {MST }}$ over the English Channel for the mean spring tide case and the difference $D_{\mathrm{SS}}$ of the skew surges obtained for the two tide scenarios (i.e. $\mathrm{SS}_{\mathrm{MST}}-$ $\mathrm{SS}_{\mathrm{MNT}}$ ). For the November 2007 event, the skew surge for the mean spring tide case $\left(\mathrm{SS}_{\mathrm{MST}}\right)$ is smaller than $0.05 \mathrm{~m}$ in the western part of the English Channel and increases toward the East, reaching more than $1 \mathrm{~m}$ at east of the Dover Strait. The skew surge difference $D_{\mathrm{SS}}$ is small (absolute value lower than $0.05 \mathrm{~m}$ ) in most parts of the English Channel at the exception of all the surroundings of the Dover 
Strait, $D_{\text {SS }}$ reaching values of about $0.20 \mathrm{~m}$ in the vicinity of Dunkerque. Considering the March 2008 event, the mean spring tide skew surge ( $\mathrm{SS}_{\mathrm{MST}}$ ) is highest in the middle of the English Channel, with $D_{\mathrm{SS}}$ values up to $0.70 \mathrm{~m}$. The skew surge difference $D_{\mathrm{SS}}$ is small (absolute value lower than 0.05 m) in most parts of the English Channel, with the exception of some UK coastal areas (e.g. the Isle of Wight), where it reaches $0.15 \mathrm{~m}$, and the Dover Strait (e.g. Dunkerque), where negative values of less than $-0.10 \mathrm{~m}$ are obtained.

These results, albeit based on a limited number of events, show that skew surges in the English Channel are tidedependent. For the selected events, this dependence appears to be weak in more or less half of the English Channel (absolute difference less than $0.05 \mathrm{~m}$ ), whereas it is significant in some UK coastal areas and over a wide area surrounding the Dover Strait, with values at Dunkerque up to $0.23 \mathrm{~m}$ for the the November 2007 case. It should be noted that for extreme tides (springest tide), the differences should be even larger. To complete the analysis, a computation is carried out focusing on the time the meteorological event occurs versus the tidal phase: we consider a mean spring tide (as above) and modify the phase lag between the tidal conditions and the meteorology by introducing a 3-h phase lag in the meteorological conditions, as compared with the original meteorological conditions. Figure 9 shows the difference between the skew storm surge for the 3-h phase lag and the skew storm surge obtained above, for a zero phase lag. In most of the English Channel, the difference is comprised between -0.05 and $+0.5 \mathrm{~m}$, whereas the difference reaches $0.20 \mathrm{~m}$ in the southern part of North Sea. Thus, the skew storm surge is also dependent on the time the storm occurs compared to the tide, with the result that the skew storm surge depends on both the tidal amplitude and tidal phase.

Regarding extreme water levels analyses in the English Channel, the most common French practice is based on the E2 approach, assuming that skew surges and tide are independent (Simon, 2007; Pugh and Vassie, 1979). The present study shows that it would be worthwhile to investigate further the tide-surge dependency in order to take better account for it in extreme water analysis. Furthermore, it confirms the need to integrate such interaction also into regional frequency analysis of extreme storm surges (Bardet et al., 2011; Bernardara et al., 2011).

\section{Conclusions}

In the framework of an effort to improve the water level forecast system along the French coast and to investigate the relevance of the various existing practises on extreme water level statistics in the English Channel, data analysis and modelling approaches have been deployed. First, preliminary data analysis on the scale of several decades indicates that the largest instantaneous storm surges occur preferentially at low and rising tide at Dunkerque, whereas this tendency is less pronounced at Saint-Malo and barely detectable at Le Conquet. In order to better identify the tide-surge dependence, numerical computations with the shallow-water model MARS have been carried out for two events (one storm from the North Sea and another from Ireland). It appears that the elevation due to tide-surge interaction is on the order of tens of centimetres in the eastern part of the English Channel, decreasing towards the west, and is practically inexistent offshore Brittany. These strong interactions can be explained by strong tidal currents around the Dover Strait and at the Cotentin headland, accompanied by shallow water depths. To better assess the consequence of the tide-surge dependence in coastal risks analysis, the skew surges are also investigated. The analysis is based on the same events (November 2007 and March 2008), but different tides are considered. It is seen that there are locations in the English Channel where skew surge is dependent on tide. This conclusion places emphasis on the relevance of preferably taking into account this dependency in extreme water level analyses in this area.

Acknowledgements. This work was jointly supported by the CPER Bretagne and BRGM. It was conducted in the framework of the Previmer project, in collaboration with IFREMER, BRGM, SHOM and METEO-FRANCE, and directed by F. Lecornu. The authors would like to thank J. Thiébot for his technical contribution, as well as L. Pineau-Guillou, R. Pedreros, P. Ohl and D. Paradis for constructive discussions.

Edited by: U. Ulbrich

Reviewed by: A. Sterl and two anonymous referees

\section{References}

Banks, J. E.: A mathematical model of a river-shallow sea system used to investigate tide, surge and their interaction in ThamesSouthern North Sea region, Philos. Trans. R. Soc. A, 275, 567609, doi:10.1098/rsta.1974.0002, 1974.

Bardet, L., Duluc, C.-M., Rebour, V., and L'Her, J.: Regional frequency analysis of extreme storm surges along the French coast, Nat. Hazards Earth Syst. Sci., 11, 1627-1639, doi:10.5194/nhess-11-1627-2011, 2011.

Bernardara, P., Andreewsky, M., and Benoit, M.: Application of regional frequency analysis to the estimation of extreme storm surges, J. Geophys. Res., 116, C02008, doi:10.1029/2010JC006229, 2011.

Blake, E. S., Rappaport, E. N., Jarrell, J. D., and Landsea, C. W.: The deadliest, costliest, and most intense United States tropical cyclones from 1851 to 2005 (and other frequently requested hurricane facts), NOAA Tech. Memo., NWS TPC-4, Syst. Dev. Off., Natl. Weather Serv., Silver Spring, Md., 48 pp., 2006.

Bertin, X., Bruneau, N., Breilh, J. F., Fortunato, A., and Karpytchev, M.: Importance of wave age and resonance in storm surges: the case of Xynthia, Ocean Model., 42, 16-30, 2012.

Charnock, H.: Wind-stress on a water surface, Q. J. Roy. Meteorol. Soc., 81, 639-640, 1955. 
Dukhovskoy, D. S. and Morey, S. L.: Simulation of the Hurricane Dennis storm surge and considerations for vertical resolution, Nat. Hazards, 58, 511-540, doi:10.1007/s11069-010-96845, 2011.

Fanjul, E. A., Gomez, B. P., and Sanchez-Arevalo, I. R.: Nivmar: a storm surge forecasting system for Spanish Waters, Scientia Marina, 65 (suppl. 1), 145-154, 2001.

Flather, R. A.: Existing operational oceanography, Coast. Eng., 41, 13-40, 2000.

Flather, R. A.: Storm surges, in: Encyclopedia of Ocean Sciences, edited by: Steele, J. H., Thorpe, S. A., and Turekian, K. K., Academic, San Diego, Calif, 2882-2892, 2001.

Gerritsen, H.: What happened in 1953? The Big Flood in the Netherlands in retrospect, Phil. Trans. R. Soc. A, 363, 12711291, doi:10.1098/rsta.2005.1568, 2005.

Glahn, B., Taylor, A., Kurkowski, N., and Shaffer, W. A.: The Role of the SLOSH Model in National Weather Service Storm Surge Forecasting, Natl. Weather Digest, 33, 3-14, 2009.

Haigh, I. D., Nicholls, R., and Wells, N.: A comparison of the main methods for estimating probabilities of extreme still water levels, Coast. Eng., 57, 838-849, 2010.

Horsburgh, K. J. and Wilson, C.: Tide-surge interaction and its role in the distribution of surge residuals in the North Sea, J. Geophys. Res., 112, C08003, doi:10.1029/2006JC004033, 2007.

Idier, D., Ehrhold, A., and Garlan, T.: Morphodynamique d'une dune sous-marine du détroit du Pas de Calais, C. R. Geosci., 334, 1079-1085, 2002.

Idier, D., Astruc, D., and Garlan, T.: Short-term spatiotemporal variability of currents over a mobile dune field in the Dover Strait, Cont. Shelf Res., 31, 1955-1966, doi:10.1016/j.csr.2011.09.006, 2011.

Lazure, P. and Dumas, F.: An external-internal mode coupling for a 3D hydrodynamical model for applications at regional scale (MARS), Adv. Water Res., 31, 233-250, 2008.

Lyard, F., Lefevre, F., Letellier, T., and Francis, O.: Modelling the global ocean tides: modern insights from FES2004, Ocean Dynam., 56, 394-415, doi:10.1007/s10236-006-0086-x, 2006.

Mazas, F. and Hamm, L.: Niveaux marins extrêmes en France : état des lieux, La Houille Blanche, 5, 5-11, doi:10.1051/lhb/2011046, 2011.

Moon, I.-J., Ginis, I., and Hara, T.: Effect of surface waves on Charnock coefficient under tropical cyclones, Geophys. Res. Lett., 31, L20302, doi:10.1029/2004GL020988, 2004.

Prandle, D. and Wolf, J.: The interaction of surge and tide in the North Sea and River Thames, Geophys. J. Roy. Astron. Soc., 55, 203-216, 1979.

Pugh, D. T.: Tides, Surges and Mean Sea-Level: A Handbook For Engineers And Scientists, John Wiley, Hoboken, N. J., 472 pp., 1987.

Pugh, D. J. and Vassie, J. M.: Extreme sea-levels from tide and surge probability. Proceedings of the Sixteenth Coastal Engineering Conference, Hamburg, German, 27 August-3 September 1978, American Society of Civil Engineers, New York, 1, 911-930, 1979.
Rascle, N. and Ardhuin, F.: A global wave parameter database for geophysical applications, Part 2: model validation with improved source term parameterization, Ocean Modell., 29, submitted, 2012.

Rego, J. L. and Li, C.: Nonlinear terms in storm surge predictions: Effect of tide and shelf geometry with case study from Hurricane Rita, J. Geophys. Res., 115, C06020, doi:10.1029/2009JC005285, 2010.

Rossiter, J. R.: Interaction between tide and surge in the Thames, Geophys. J. R. Astron. Soc., 6, 29-53, 1961.

SHOM: Tidal streams and tidal heights: The Channel form Dunkerque to Brest, 564-UJA, ISN 2-11-088251-4, 2000.

SHOM: SHOMAR - Tidal prediction software, Edn. 2010-2011, ISBN 978-2-11-097251-4, 2009.

Simon, B.: La Marée Océanique Côtière. Institut Océanographique, ISBN: 2903581320, in French with an English translation in preparation, 2007.

Simon, B., Pineau-Guillou, L., Perherin, C., Goasguen, G., and Simon, A.: Les niveaux marins extrêmes le long des côtes de France et leur évolution, Rapport SHOM-Cetmef, 2008.

Sterl, A., van den Brink, H., de Vries, H., Haarsma, R., and van Meijgaard, E.: An ensemble study of extreme storm surge related water levels in the North Sea in a changing climate, Ocean Sci., 5, 369-378, doi:10.5194/os-5-369-2009, 2009.

Tolman, H. L.: User manual and system documentation of WAVEWATCH-III version 3.14, NOAA/NWS/NCEP/OMB Tech. N. 276, Natl. Oceanic and Atmos. Admin., Silver Spring, Md., 220 pp., 2009.

Van Den Brink, H. W., Konnen, G. P., and Opsteegh, J. D.: The reliability of extreme surge levels, estimated from observational records of order hundred years, J. Coastal Res., 19, 376-388, 2003.

Van Den Brink, H. W., Konnen, G. P., and Opsteegh, J. D.: Uncertainties in extreme surge levels estimates from observational records, Philos. T. Roy. Soc. A, 363, 1377-1386, 2005.

Von Storch, H., Gönnert, G., Meine, M., and Woth, K.: Storm surges - an option for Hamburg, Germany, to mitigate expected future aggravation of risk, Environ. Sci. Policy., 11, 735-742, doi:10.1016/j.envsci.2008.08.003, 2008.

Wolf, J.: Interaction of tide and surge in a semi-infinite uniform channel, with application to surge propagation down the east coast of Britain, Appl. Math. Modelling, 2, 245-253, 1978.

Zhang, W.-Z., Shi, F., Hong, H.-S., Shang, S.-P., and Kirby, J. T.: Tide-surge Interaction Intensified by the Taiwan Strait, J. Geophys. Res., 115, C06012, doi:10.1029/2009JC005762, 2010.

Zweers, N. C., Makin, V. K., de Vries, J. W., and Burgers, G.: On the influence of changes in the drag relation on surface wind speeds and storm surge forecasts, Nat. Hazards, 62, 207-219, doi:10.1007/s11069-011-9989-z, 2012. 